\title{
Goddard Atmospheric Composition Data Center: Aura Data and Services in One Place
}

\author{
G. Leptoukh, S. Kempler, I. Gerasimov, S. Ahmad, J. Johnson \\ Goddard Earth Sciences Data and Information Services Center, Code 610.2, NASA GSFC, Greenbelt, Maryland 20771, USA
}

\begin{abstract}
The Goddard Atmospheric Composition Data and Information Services Center (AC-DISC) is a portal to the Atmospheric Composition specific, user driven, multi-sensor, on-line, easy access archive and distribution system employing data analysis and visualization, data mining, and other user requested techniques for the better science data usage. It provides convenient access to Atmospheric Composition data and information from various remote-sensing missions, from TOMS, UARS, MODIS, and AIRS, to the most recent data from Aura OMI, MLS, HIRDLS (once these datasets are released to the public), as well as Atmospheric Composition datasets residing at other remote archive site.
\end{abstract}

Keywords: atmospheric composition; Aura; data center; data services, TOMS, UARS, MODIS, AIRS, OMI, MLS, HIRDLS

\section{INTRODUCTION}

Studying Atmospheric Composition using Earth science data sets from multiple sources can be a daunting task. It involves identifying appropriate geophysical parameters, then trying to understand what datasets contain these parameters, then locating at various locations, and then obtaining voluminous amounts of data, subsetting to extract the parameters and spatial areas desired, and co-locating the data with other data. Thus, there is often a significant upfront investment before the core investigation can begin. To ease the burden of such investigations among the Atmospheric Composition community, the Goddard Earth Science (GES) Data and Information Services Center (DISC) has undertaken the development of the Atmospheric Composition Data and Information Services Center (ACDISC). AC-DISC (http://acdisc.gsfc.nasa.gov/) is a portal to the Atmospheric Composition (AC) specific, user driven, multi-sensor, on-line, easy access archive and distribution system employing data analysis and visualization, data mining, and other user requested techniques for the better science data usage. It provides convenient access to $\mathrm{AC}$ data and information from various remote-sensing missions, from TOMS, UARS, MODIS, and AIRS datasets, to the most recent data from Aura OMI, MLS, HIRDLS, as well as AC datasets residing at other remote archive sites. It adequately addresses the NASA Strategic Atmospheric Composition Roadmap.

The goals of the AC-DISC are:

- Serve as a one-stop shopping data center for Atmospheric Composition (AC) Scientists, guided by Atmospheric Composition Scientists

- Provide services and expertise for effortless and convenient access to and usage of $\mathrm{AC}$ data
- Collaborate with AC scientists to establish a framework for seamless utilization of data from multiple sensors for long-term atmospheric research

\section{AC-DISC APPROACH}

- $\mathrm{AC}$ scientist guided - $\mathrm{AC}$ community representatives make suggestions and evaluate results

- Multi-sensor - Archive and distribute AC data from multiple sensors to facilitate long term, AC-specific research.

- On-line archive - Allows for direct retrieval of data via ftp.

- Web-based access - Reuses popular and easy to use GES DISC home grown interfaces

- On-line analysis and visualization - Reuses popular customizable tool (Giovanni) for on-line analysis and visualization.

- Subsetting tools - Allows retrieval of smaller volume data.

- Data mining tools - Removes data reduction burden from scientist - run your algorithm next to the data and retrieve results only.

- Data safely stewarded - Ensures all AC data and documentation is safely kept for long-term science objectives.

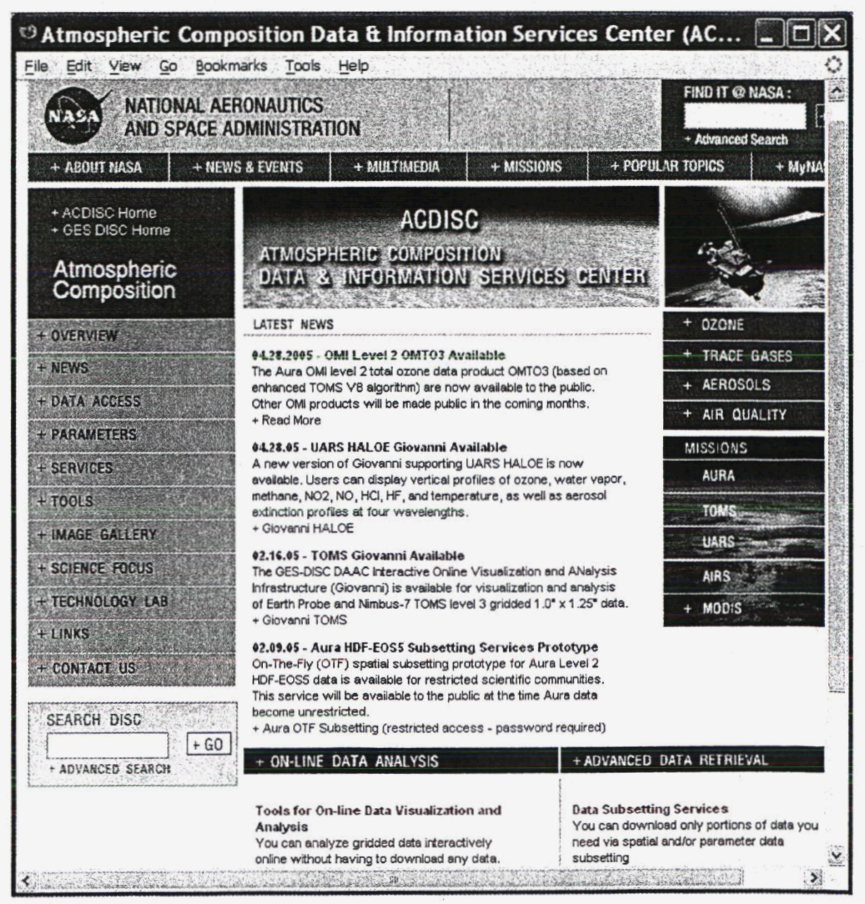

Figure 1. Goddard AC-DISC home page 


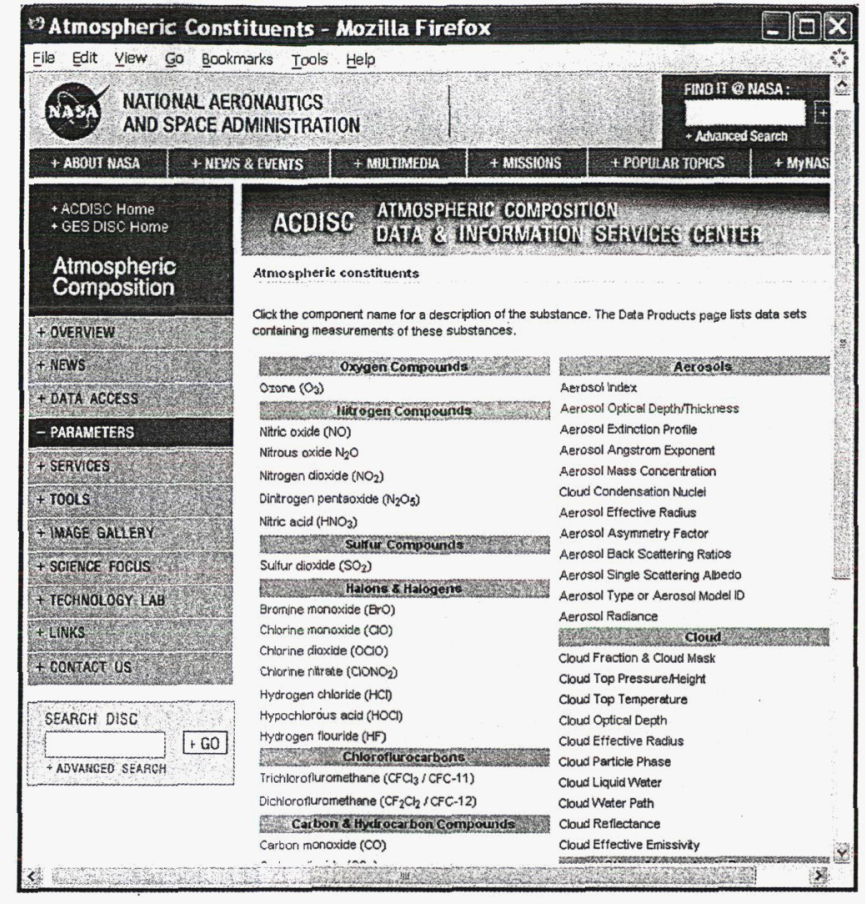

Figure 2. AC-DISC Parameters page

\section{AURA DATA AT AC-DISC}

Aura is the EOS chemistry mission which aims to answer three important questions: is the ozone layer recovering, is air quality getting worse, and is the Earth's climate changing? Aura will continue the long term series of atmospheric chemistry measurements made by earlier missions. The Aura spacecraft operates in a $705 \mathrm{~km}$ sun-synchronous polar orbit, with an ascending equator crossing at 1:45 PM. The satellite carries four state-of-the-art instruments:

\section{High Resolution Dynamics Limb Sounder (HIRDLS)}

\section{Microwave Limb Sounder (MLS)}

\section{Ozone Monitoring Instrument (OMI)}

\section{Tropospheric Emission Spectrometer (TES)}

Data from HIRDLS, MLS and OMI will be available from the GES DISC, whereas data from the TES instrument will be available from another DAAC located at NASA Langley Research Center.

\section{HDF-EOS5 SUBSETTING}

One of the challenges in handling Aura data is that the majority of Aura data products are packed in the so-called HDF-EOS5 data format, which is different from HDF4based HDF-EOS typical for data from previous EOS missions. HDF5 is a general-purpose library and file format for storing scientific data.

To provide subsetting services for Aura data, the HDFEOS5 subsetter has been developed at the AC-DISC. It is written in C Code using HDF-EOS5 libraries. It supports any properly formatted HDF-EOS5 file, and runs from the command line.
The following subsetting options are currently supported:

- Parameter (i.e. field)

- Spatial Box

- Vertical Range (or dimension)

- Temporal Range

- Object Type (i.e. Swath, Grid, Point, Zonal Average)

The original Metadata/Attributes retained during subsetting.

Currently, the subsetter works in Subscription Mode, i.e. runs as a Product Generation Executable (PGE) (or in production mode), triggered by standing order. In addition, it can be used for ad-hoc subsetting. It also has been implemented within the on-the-fly prototype developed to subset during FTP download. In the future, it will be implemented into the on-demand for near-line archived data using PGE subscription method.

\section{GIOVANNI}

The goal of the GES-DISC Interactive Online Visualization and Analysis Infrastructure (Giovanni) is to relieve the science investigator of some of the upfront data preparation work and provide a tool for obtaining science knowledge via plots, graphs, and tables without having to download and prepare large amounts of data.

The principal design goal for Giovanni $[1,2]$ was to provide a quick and simple interactive means for science data users to study various phenomena by trying various combinations of parameters measured by different instruments, arrive at a conclusion, and then generate graphs suitable for a publication. Alternatively, Giovanni would provide a means to ask relevant what-if questions and get back answers that would stimulate further investigations. This would all be done without having to download and preprocess large amounts of data. Another goal of Giovanni was to off-load as much as possible the data processing workload onto the machines hosting the data and to reduce data transfers to a minimum.

Giovanni supports HDF, HDF-EOS, as well as binary formats.

\section{A. Giovanni User Interface}

From the user's perspective, Giovanni is a simple Web application. A user can select either the Java or non-Java version. The resulting Web page allows the user to select the spatial area via the Java image map applet or, if the non-Java version was selected, manually by entering in coordinates defining a bounding box. The user also selects the temporal range of the data, one or more parameters from this data set, and the output type (ASCII or one of several plot types).

Depending upon the parameters selected, the vast majority of users will see the results in a matter of seconds. For users who choose large amounts of data either spatially or temporally, the results may take several minutes. 


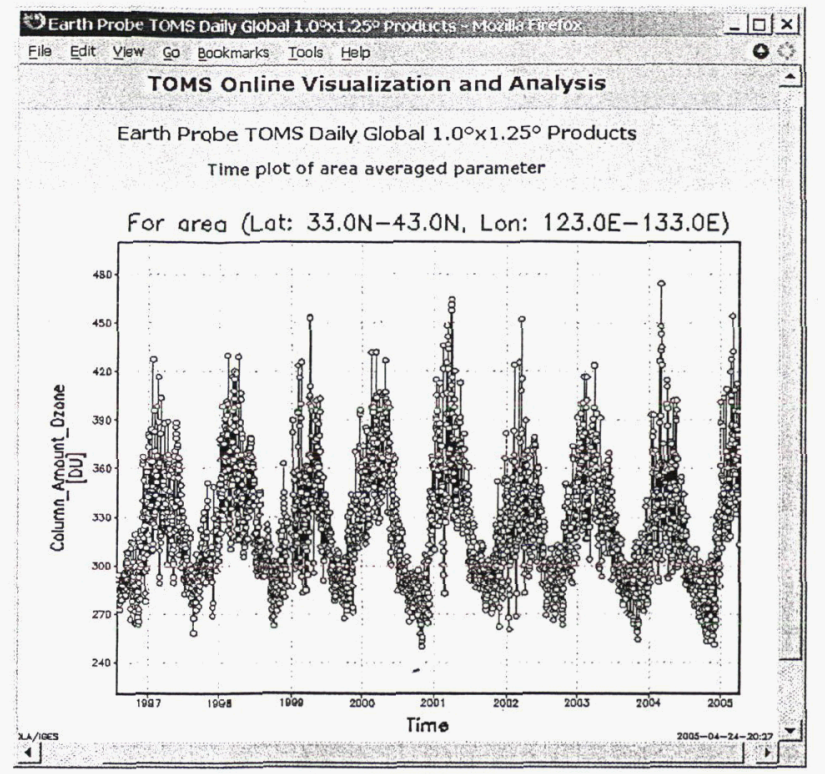

Figure 3. Example of Giovanni time-series for Earth Probe TOMS Ozone Column over Korean Penninsula in 1996-2005

Giovanni allows scientists and researchers to easily access, visualize and analyze various gridded Level-3 atmospheric products, thus helping them to understand seasonal-to-interannual variation of atmospheric parameters. Giovanni can provide information at every single point and in any rectangular area within the data domain, which allows researchers to conduct nearly unlimited investigations. The ASCII output option allows users to do their own customized analyses or applications.

With HALOE and AIRS, the AC-DISC has moved into visualization and analysis of vertical profiles and zonal averages in preparation for handling OMI, MLS and HIRDLS vertical profiles.

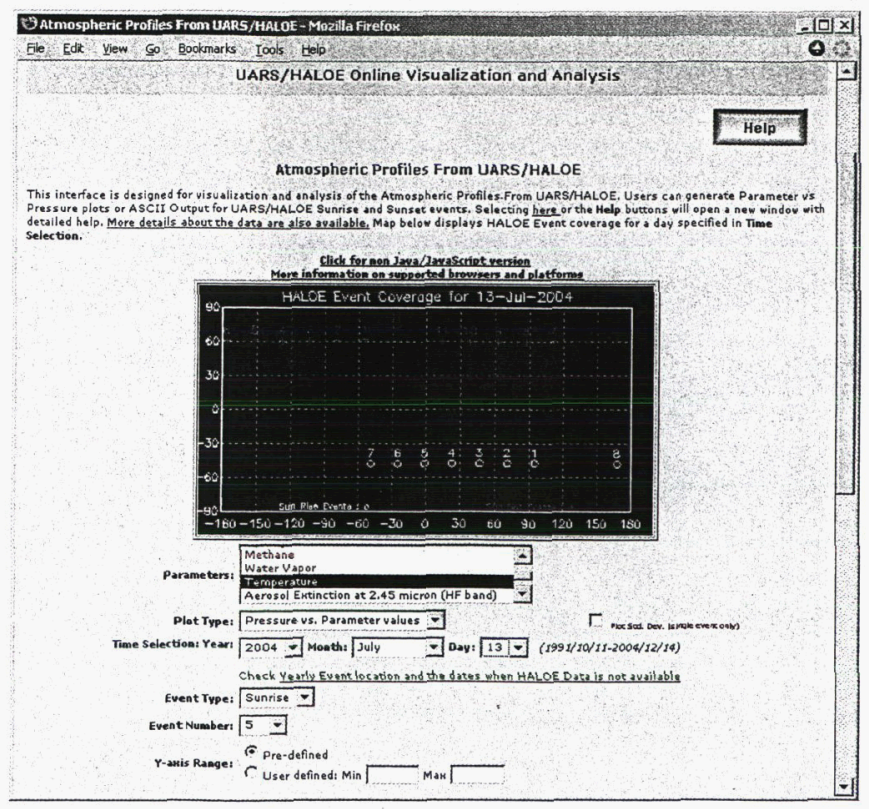

Figure 4. Example of UARS HALOE event selection page

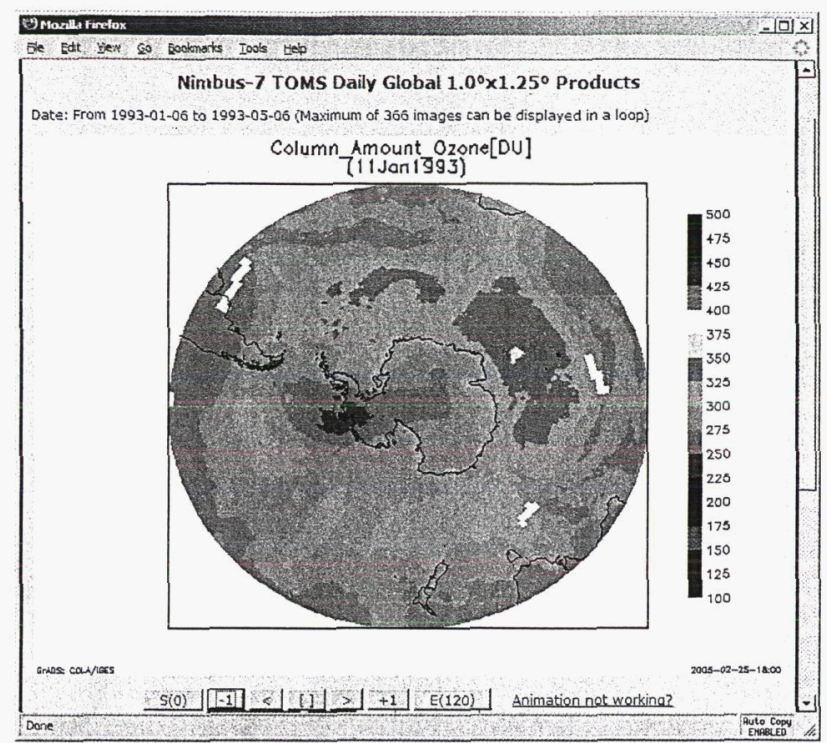

Figure 5. Example of Giovanni area map for Nimbus-7 TOMS Ozone Column over Antarctica, January 11, 1993

\section{B. TOMS Giovanni}

TOMS from Nimbus-7 and Eearth Probe were the first Atmospheric Composition daily datasets implemented in Giovanni. Fig. 3 shows 12-year time-series of Ozone total column amount over Korea with early spring peaks every year. Fig. 5 shows convenient presentation of Ozone total column in polar area in polar projection.

\section{HALOE Giovanni}

A new version of Giovanni supporting UARS HALOE is now available. Users can display vertical profiles of ozone, water vapor, methane, $\mathrm{NO} 2, \mathrm{NO}, \mathrm{HCl}, \mathrm{HF}$, and temperature, as well as aerosol extinction profiles at four wavelengths. Fig. 4 shows a map with sunrise and sunset events for a given day that helps users to pick the right event.

\section{AIRS Giovanni}

AIRS is the first Giovanni instance where various vertical and horizontal 2D slices are employed within a single Giovanni instance. The first AIRS release deals with daily slices only. Fig. 6 presents the temperature horizontal slice at $50 \mathrm{hPa}$ over Korea, while Fig. 7 shows temperature vertical cross-section at $127^{\circ}$ meridian. Fig. 8 provides temperature vertical profile at a single lat/lon point, which can conveniently compared with sonde measurements. In the next release, the time-series and spatial/vertical averages will be implemented.

\section{E. Aura Giovanni}

AC-DISC will soon start working towards implementation of OMI Ozone into Giovanni. It will utilize OMI L2G daily product that will contain the OMI L2 data binned onto a $0.25^{\circ} \times 0.25^{\circ}$ grid. OMI L3 products with this and coarser resolutions in time and on Earth's surface can be derived from the $\mathrm{L} 2 \mathrm{G}$ product and incorporated into Giovanni. 


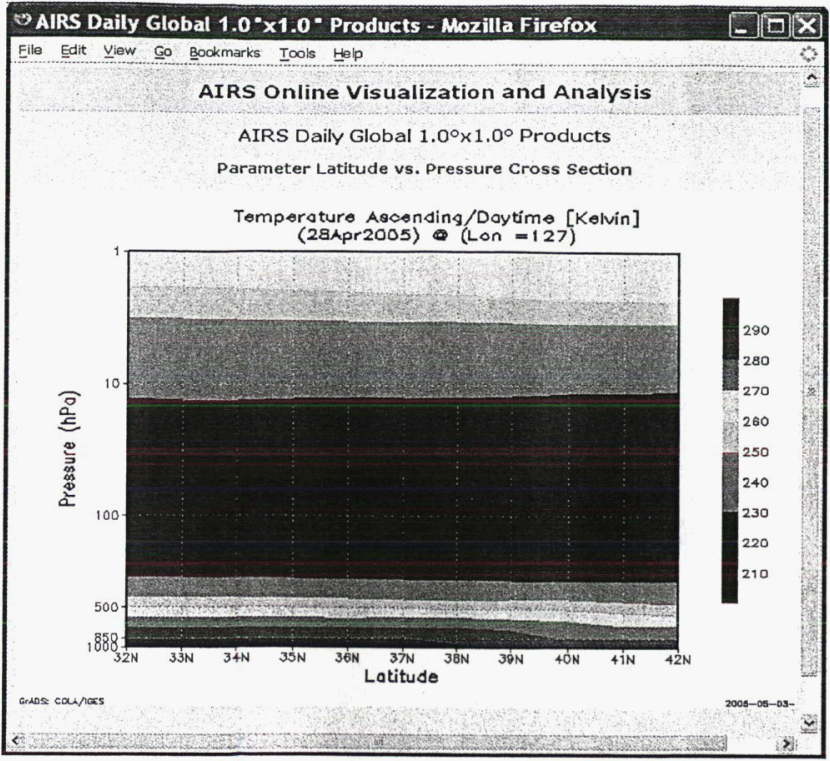

Figure 6. AIRS Temperature Cross section (pressure level vs. latitude) at longitude $=127 \mathrm{deg}$ (meridian cross-section through Korean peninsula) for April 28, 2005

\section{F. Other Giovanni instances}

- MOVAS: MODIS aerosol related

- Ocean-color (SeaWiFS and MODIS Aqua)

- TOVAS: TRMM and other gridded precipitation data

\section{CURRENT AC-DISC STATUS}

The first AC-DISC release (April 2005) provides access to TOMS, UARS, AIRS and MODIS data along with documentation on all publicly release Atmospheric Composition data at the GES DISC. The first AC-DISC Giovanni instances deal with TOMS and HALOE data. The first OMI data product OMTO3 (OMI/Aura Ozone (O3) Total Column 1-Orbit L2 Swath $13 \times 24 \mathrm{~km})$ was released on April 28, 2005.

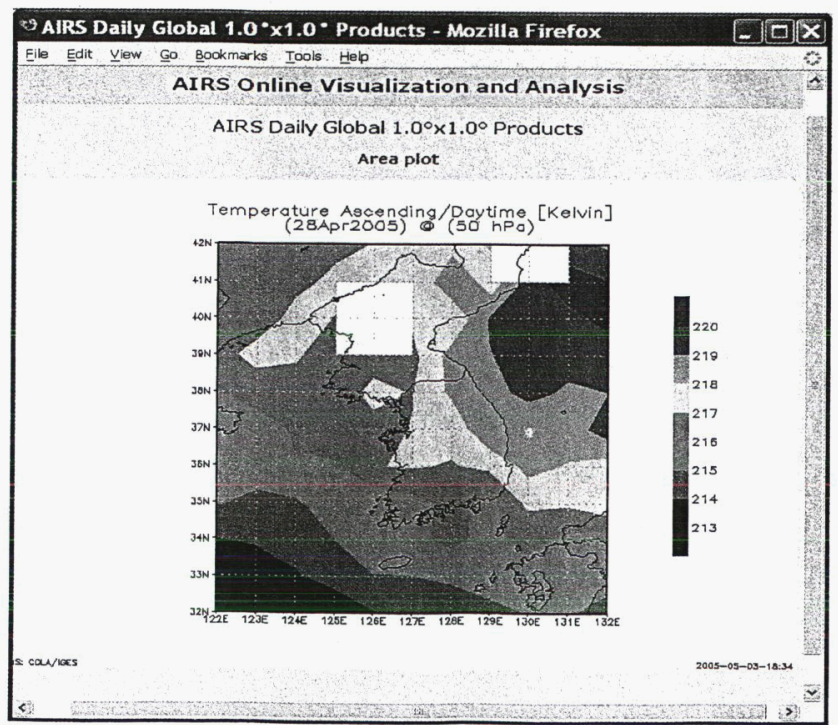

Figure 7. AIRS Temperature area map over Korea, April 28, 2005

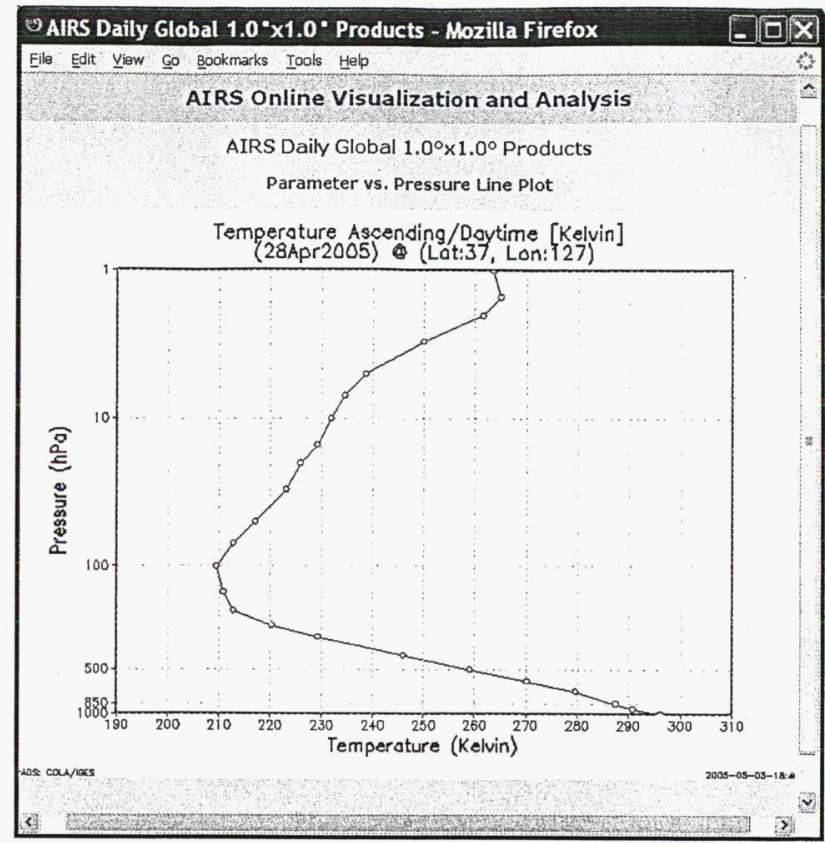

Figure 8. AIRS Temperature profile at a single point (latitude $=37^{\circ}$, longitude $\left.=127^{\circ}\right)$, April 28, 2005

\section{FUTURE DiRECTIONS}

In the near-term, the AIRS time-series and various averaging options will be implemented in Giovanni. Once OMI Level $2 \mathrm{G}$ product is made available, it will be processed into Level 3 product suitable for Giovanni, and implemented into an OMI instance. Various intercomparison options will be employed to compare and complement TOMS, OMI and parameters from other data products.

Current implementation of Data Access is based on the existing components not yet fully integrated into a single streamlined interface. In the future releases, we intend to reduce significantly the number of "clicks" needed to acquire the desired geophysical parameters.

\section{REFERENCES}

[1] J.G. Acker, L.W. Harding, G. Leptoukh, T. Zhu, S. Shen, "Remotelysensed chl a at the Chesapeake Bay mouth is correlated with annual freshwater flow to Chesapeake Bay," Geophysical Research Letters, vol 32, L05601, February 2005

[2] S. Berrick, G. Leptoukh et al., "Multi-sensor distributive on-line processing, visualization and analysis system," IGARSS'04, Proceedings, III: 2030-2033, 2004

\section{ACKNOWLEDGMENT}

The AC-DISC wishes to thank Drs. M. Schoeberl, A. Douglass, P.K. Bhartia, E. Hilsenrath (NASA GSFC) for their support of the AC-DISC effort.

\section{AC-DISC URL: $\underline{\text { http://acdisc.gsfc.nasa.gov }}$}

